\title{
Paradoxos do ensino de literatura
}

Conceição Aparecida Bento ${ }^{a}$

\begin{abstract}
Resumo
Este texto parte de uma concepção que associa a literatura à instabilidade. Diante dessa ideia, aponta-se a impossibilidade do ensino de literatura e propõe-se, como alternativa, a frequência à literatura nos espaços de ensino. Essa frequência não se traduz na proposta de leitura solitária dos tex tos literários pelos alunos, mas na presença dessa leitura no espaço de sala de aula.
\end{abstract}

Palavras-chave: Ensino, literatura, leitura. 
No capítulo "O Campo de Croquet da Rainha", do livro Alice no País das Maravilhas, a ordem da monarca - "Cortem-lhe a cabeça" (CARROLL, 1980, p. 99) - deixa a todos perplexos, pois o gato só possui cabeça. A questão é como decapitar um animal que só possui essa parte do corpo, se o verbo decapitar indica cortar, eliminar a cabeça. Eis um dos paradoxos do texto. Só é possível decapitar, cortar a cabeça, daqueles que a possuem ligada a um corpo; esse não é o caso do amigo de Alice, que, no final do capítulo, desvanece-se rindo, possivelmente, da pseudoautoridade da rainha. A ironia denuncia, por meio da inadequação linguística, a impossibilidade da execução da ordem. Ao lado do sentido denotativo do verbo, é possível fazer remissão ao metafórico, indicando a anulação de ato ou de poder de um chefe. A iminente degola do gato transforma-se na da monarca.

A questão apresentada neste texto - o ensino de literatura - assemelha-se ao episódio do livro de Carroll. O binômio ensino/literatura, articulado pela preposição de, pressupõe a existência de algo que possa ser definido, ou seja, que tenha suas fronteiras delimitadas. No caso da literatura, essa, como a ordem da rainha, é uma tarefa difícil de executar. O intuito, ao propor essa analogia, não é afirmar a aporia e cair na inação. O objetivo é pensar os elementos associados ao problema; colocá-lo e posicionar-se diante dele.

Definir a literatura é daquelas tarefas árduas, senão impossíveis. Já se tentou demarcar seu território a partir da diferença entre textos escritos e orais. Meschonnic revê essa tentativa e aponta uma espécie de quadratura do círculo, em seus desdobramentos:

Jadis on opposait l'oralité - que d'ailleurs on ne designait pas ainsi - à littérature. Comme la voix, la vive voix, à la lettre, qui est morte, ou qui tue. La littérature était écrite, par définition. Quand les éthnologues se sont mis a parler de littérature orales, rien n'a changé. Sinon qu'on recueillait par écrit ce qui jusque-là n'avait été porté que par la voix (MESCHONNIC, 2006, p. 287).

Defini-la associando-a a um viés crítico é também insuficiente, dadas as abordagens possíveis do texto literário: as já conhecidas e que, portanto, não achamos problemático vincular à literatura - viés sociológico, antropológico, psicanalítico -, as que estão em evidência e as que virão, certamente, oferecem 
e oferecerão elementos para que se pense a literatura, mas nenhuma dessas abordagens a capta; e a adesão a uma delas é um exercício temerário, pois parcial.

Diante da dificuldade de alcançar uma possível definição, escolho três tentativas de aproximar-se dessa tarefa. São três afirmações sobre a literatura. Nelas, há o reconhecimento da complexidade do literário e, diante disso, evidenciam a necessidade de um desarranjo lógico para explicitá-lo.

A primeira é a do crítico Ezra Pound, em o $A B C$ da Literatura. Nessa obra, Pound afirma ser a literatura a "linguagem carregada de significado", ou seja, a "novidade que permanece novidade" (POUND, 1977, p. 33). A segunda tentativa é a de Barthes, em Aula. Na conferência inaugural no Collège de France, em 1977, ele afirma entender por literatura "não um corpo, uma sequência de obras, nem mesmo um setor de comércio ou de ensino, mas o grafo complexo das pegadas de uma prática, a prática de escrever" (BARTHES, 1997, p. 16-7), prática que se traduz no contínuo "aflorar da língua", no trabalho ininterrupto de deslocamentos realizados em seu interior. A terceira proposta é de Blanchot, em Le Livre à Venir: "l'essence de la littérature, c'est d'échapper à toute détermination essentielle, à toute affirmation qui la stabilise ou mème la réalise: elle n'est jamais déjà lá, elle est toujours à retrouver ou à reinventer." (BLANCHOT, 2003, p. 273). As três aproximações furtam-se a estabilizações; elas possuem, como traço comum, a instabilidade e seu caráter de deslizamento no interior da língua.

O paradoxo poundiano, a união dos elementos díspares - a novidade que permanece novidade -, sintetiza bem esse ser que se define na ação, no sendo, no devir, alcançando, assim, um viés que não o substancializa, mas o faz existir em seu exercício.

A proposta de Barthes alia a literatura a uma prática - a da escritura - e a desconecta de um ramo de ensino ou de uma série de obras. Barthes, em sua proposta, associa a literatura ao corpo - ao ato da escritura -, e essa ação pressupõe outra - a da leitura. Abre-se, dessa forma, espaço para pensar a literatura vinculada ao modo como o corpo é exigido para sua recepção. Embora isso pareça simples, não é, pois a proposta vincula a literatura a uma corporeidade que não é a da obra ou sequência de obras atreladas a um saber pré-determinado; é a de um corpo que recepciona e assegura a existência da obra. Esse corpo não é abstrato, é um corpo concreto, que dá estatuto 
à literatura, no momento em que a realiza durante a leitura, e a propaga no instante em que escreve. Esse corpo também se afirma, quando fala sobre ela: mãos, olhos e boca afirmam, assim, a literatura.

Semelhante à caracterização de Pound e Barthes, Blanchot inscreve a literatura fora das determinações identitárias e não privilegia, em sua proposição, elementos externos ou internos à obra: o traço que permanece, em Blanchot e em Pound, é o que nega o caráter de permanência.

Se a literatura explicita-se por meio de sua instabilidade, por seu sendo contínuo, por sua recriação e reinvenção a cada obra, parece um paradoxo a existência de um ensino de literatura que mire a explicitação de um objeto que só se diz pelo trânsito de seu ser. Não se pode afirmar o ser da literatura tal como o ensino o desenha, seguindo a lógica do se a, então $b$, porque esse ser, nesses termos, não existe; do mesmo modo como não se pode decapitar um gato apenas com cabeça. Esse é o primeiro ponto a ser analisado: o vínculo de um elemento instável a um ensino organizado a partir da ideia da transmissão de conteúdos. É difícil inserir a literatura nesse viés, pois há uma incompatibilidade entre o realizado de modo geral pelas escolas e o proposto pela obra literária. O que se afirma, nas instituições de ensino, sobre a literatura é sua negação.

A questão é, assim, o que se faz quando se diz ensinar a literatura, se não há o ser da literatura, como substância que possa se dizer fora do sendo que a caracteriza. Barthes afirma que esse ensino é o da história da literatura e, pensando na literatura francesa, como todas, aliás, essa história é carregada de ideologia. Entre nós, ele é menos história da literatura, mas lá, como aqui, esse ensino trai sua denominação; pois. não é o ensino de literatura, mas um ensino sobre a literatura. Fala-se sobre ela, e nisso usa-se um metadiscurso distante de sua mobilidade, e insiste-se num estruturalismo ou numa sociologia redutores. O ensino, normalmente, bate na tecla dos chamados elementos estruturais da narrativa - as personagens, seus atributos, as categorias de tempo e espaço -, ou na relevância de aspectos sociais presentes na obra, que estão nela e têm sua importância. Há ainda os que insistem, de forma mais ou menos explícita, na chamada intenção do autor, no significado do texto. 
Esse ensino fala sobre literatura e, por mais que tente explicitá-la por meio de categorias metadiscursivas, não se encontra com ela. Ele reforça a antinomia entre ensino e literatura; mais grave, deforma o objeto que pretende alcançar.

Assim, não causa estranheza que os estudantes cheguem ao ensino superior - mesmo os aspirantes ao curso de Letras -, identificando a literatura com as escolas literárias - tomando como natural uma taxonomia com forte viés ideológico -, ou julgando a leitura do texto literário um ato a serviço da intelecção de um suposto significado, seja o que o autor quis apresentar, seja o que os elementos internos organizam.

O modo como esse ensino se realiza desconfigura não apenas a literatura, ao tentar formatá-la, mas, também, os discursos produzidos sobre ela, ao simplificá-los em demasia. $\mathrm{O}$ que ocorre é um achatamento do texto literário a uma visão, e sua redução a uma coordenada que, na cabeça dos estudantes, ganha ar de suficiência. Uma das causas dessa deturpação é a má formação dos professores, má formação pela qual responde não só o ensino superior, mas a formação inicial e média. Muito do jogo se resolve nessas etapas, e sabe-se que elas são um desastre. Não sejamos ingênuos e redutores, entretanto. As simplificações da literatura articulam-se a outros elementos, e esses repercutem inclusive sobre as deficiências dessa formação. Penso nos interesses das editoras de livros didáticos, negócio muito lucrativo, que transforma a literatura em excertos comentados; penso nas avaliações dos vestibulares, transformados em grandes negócios, trabalhando com uma "lista dos mais mais", numa parada de sucesso ineficaz e fora de lugar. Esses agenciamentos associam o ensino a uma concepção mercantil e instrumental, incompatível com a lentidão exigida pela complexidade da leitura literária.

Diante dos paradoxos e deturpações apresentados, defendo a inserção da literatura nos espaços de ensino, não como um objeto sobre o qual se fala, mas como um objeto que se frequenta. Não se deve priorizar o discurso sobre a literatura, e sim o discurso móvel, oscilante, disjuntivo, complexo e inquietante $d a$ obra literária.

A proposta é dar voz à literatura no espaço escolar. É inseri-la nesse espaço, ouvi-la, fazê-la objeto de leitura. Transitar por esse objeto é algo que se exercita, e isso não será feito pedindo que o aluno leia o texto em casa, ou que nele 
identifique personagens, enredo, tempo ou outros elementos. A inserção da literatura nas escolas, com as caracterizações já delineadas, dar-se-á pela frequência ao objeto e não por uma atividade metadiscursiva.

Não adianta fazer da leitura do texto literário um dever de casa, que se esgota na solidão, ou na avaliação realizada pelo professor do texto escrito do aluno. Temos uma tradição que associa a leitura ao silêncio e aos espaços da intimidade. Do espanto de Santo Agostinho, observando o descanso da voz e da língua na leitura silenciosa de Santo Ambrósio, ao narrador da Recherche que se refugia no gabinete sanitário, para vivenciar a solidão, temos uma longa história em que a leitura prescinde da voz e da presença do outro.

Nas escolas, ao contrário, ela deve ser audível. Essa audibilidade deve dar voz à polissemia do texto, abrir espaço para discussões, cisões, análises e inferências variadas, propiciar diálogos entre textos. As personagens, o espaço, o contexto histórico, a intertextualidade podem aparecer nessas discussões; eles não devem, no entanto, preceder ou justificar, a priori, a leitura do texto literário. Chega-se a esses elementos a partir da obra, não se deve partir deles.

O aluno não é o crítico, no entanto não seria mal que se portasse como ele; não para julgar a obra, mas para falar e escrever sobre ela. Que o aluno, como o crítico, fosse aquele que não escrevesse ou falasse sem ler, e não lesse senão para escrever ou falar ${ }^{1}$. A extensão da obra no espaço de ensino, utilizando as ideias de Barthes, ocorreria a partir do corpo daquele que a frequentou: da mão que escreveu sobre ela; do olho que a leu e da voz que a discutiu ou a apresentou ao outro.

Parece um objetivo simples, mas ele não se realiza e leva à indagação de por que, embora seja consenso o desejo de formar leitores de textos literários, essa leitura se faz tão pouco presente entre nós. Novamente, as linhas de força são múltiplas e, além das já apresentadas, assinalo outra, que reafirma o teor daquelas - o vestibular, as editoras, que coexistem com a escola, mas se localizam fora dela -, a lógica fabril que adentrou os locais de ensino. Eles assumiram os ditames

1 Uso, de modo deformado, uma imagem de Blanchot no prefácio de Lautréamont y Sade, a respeito do crítico. da relação empresarial. Almeja-se, nesses espaços, o volume da produção das empresas, como se este fosse compatível com o saber. Nos níveis iniciais, preconizam-se os cadernos cheios de anotações, repletos de conteúdos. Muita informação 
traduz-se em pouco saber. Nas universidades, o espaço para a literatura é pequeno. Os cursos de Letras, em extinção, são o lugar restrito de sua presença. Os professores desses cursos tentam equilibrar-se entre a necessidade de recaracterizar a literatura, tal a quantidade de disparates das concepções dos alunos, e a necessidade - desmesurada, em alguns casos - de discutir os elementos teóricos. Muitas vezes, nesses cursos - nas Universidades particulares, eles são de licenciatura e, majoritariamente, possuem três anos -, pouco sobra para a leitura do texto literário. Cria-se, assim, o círculo vicioso do desastre; sobretudo se pensarmos que muitos dos professores do ensino superior já se formaram nesse distanciamento e falam de um objeto pouco frequentado por eles.

Sem a frequência à literatura, de nada adiantam propostas de inversão da cronologia na abordagem do texto literário, de leituras intertextuais ou de organização temática dos conteúdos. Sem a presença da voz do texto literário, as aulas de literatura representam um equívoco, não apenas em sua denominação. Mais sério que isso, como afirma Barthes, nelas inscreve-se a alienação do saber. Acredita-se, nesses espaços de ensino, que se conhece a literatura e se está diante dela. O paradoxo do gato de Alice no País das Maravilhas não é, para muitos dos atores dessa cena - professores e alunos -, nem mesmo uma miragem. Julgam ser possível o ensino de literatura; e, pior, julgam ter acesso a ela.

Ter acesso à literatura é se apropriar de uma dimensão da linguagem distante da instrumentalização que a linguagem atingiu entre nós; uma dimensão que não a faz mero meio de utilidades e fins que atravessa o discurso pedagógico e outros discursos. "As palavras não são ferramentas; mas damos às crianças linguagem, canetas e cadernos, assim como damos pás e picaretes aos operários." (DELEUZE e GUATTARI, 1995, p. 12).

Não é aleatório que o vocabulário comercial adentre o vocabulário pedagógico e seja usado sem indignação por aqueles que deveriam fazer frente a ele. O chamado "contrato pedagógico" é um exemplo de ideia fora do lugar, mas, infelizmente, não fora de seu tempo. A metáfora que gradativamente toma ares de elemento da natureza faz pensar na venda e compra de mercadorias, faz pensar em determinações, a priori, numa relação com muitos pressupostos e, quando se afirma isso aqui, não se deve pensar nas possíveis injunções de ordem pessoal 
que fazem a dinâmica da sala de aula descambar num pseudofamiliarismo ou cristianismo também fora do lugar. O que está em jogo são as múltiplas possibilidades de abordagem e de discussão do texto literário e, quiçá, das ciências humanas. Faz par com o "contrato pedagógico", a produtividade que transforma professores e alunos num operariado para lá de alienado, e sofistica o "capitalismo selvagem". Esse novo operariado se aliena de seu produto e dos elementos envolvidos em seu trabalho, que, lento por natureza, deveria vincular-se à ruminação e não à reprodução desenfreada.

Por isso, uma discussão sobre a relação ensino e literatura, mais que uma discussão de como se pode arranjar o currículo ou sobre os autores escolhidos ou abordagens possíveis, ou seja, uma discussão para tentar "arrumar a casa" e melhorar os índices em avaliações internacionais, pressupõe e exige uma problematização da linguagem e, associada a isso, uma concepção sobre o "sendo" da literatura.

\section{REFERÊNCIAS}

BARTHES, R. Aula. São Paulo: Cultrix, 1997.

O Rumor da Lingua. São Paulo: Martins Fontes, 2004.

BLANCHOT, M. Lautréamont y Sade. México: Fondo de Cultura Económica, 1990.

. Le Livre à Venir. Paris: Gallimard, 2003.

CARROLL, L. Aventuras de Alice. São Paulo: Summus, 1980.

DELEUZE e GUATTARI, F. Mil Platôs (vol. 2). São Paulo: Editora 34, 1995.

MESCHONNIC, H. La Rime et la Vie. Paris: Gallimard, 2006, POUND, E. ABC da Literatura. São Paulo: Cultrix, 1977. 


\section{Abstract}

\section{Literature teaching paradoxes}

This text assumes that literature is associated to instability. From this idea, it is pointed the impossibility of teaching literature and it is proposed, as an alternative, the literature attendance in teaching spaces. This attendance is not translated into a proposal of an alone reading of the literary texts by the students, but the presence of this reading in the space of the classroom.

Keywords: teaching, literature, reading. 